\title{
DETERMINATION OF ORGANOPHOSPHORUS PESTICIDE RESIDUES IN MILK
}

\author{
TOMASZ KILJANEK, ALICJA NIEWIADOWSKA, AND STANISŁAW SEMENIUK \\ Department of Pharmacology and Toxicology, \\ National Veterinary Research Institute, 24-100 Pulawy, Poland \\ tomasz.kiljanek@piwet.pulawy.pl
}

Received: January 11, 2013

Accepted: May 2, 2013

\begin{abstract}
A method for simultaneous determination of 13 organophosphorus pesticide residues in milk samples has been developed and validated. The method is based on the extraction of the sample with acetone and petroleum ether, cleanup by gel permeation chromatography, and solid phase extraction, and determination by gas chromatography with flame photometric detection. The recovery, investigated by analysing blank milk samples spiked with azinphos, chlorfenvinphos, chlorpyrifos, chlorpyrifos-methyl, diazinon, fenitrothion, methacrifos, methidathion, parathion-methyl, pyrazophos, and triazophos at concentrations of 10, 20, and 30 $\mu \mathrm{g} / \mathrm{kg}$, and with parathion and pirimiphos-methyl at concentrations of 25,50 , and $75 \mu \mathrm{g} / \mathrm{kg}$, ranged from $73.1 \%$ to $106.2 \%$. Performance characteristics, such as repeatability and within-laboratory reproducibility expressed as coefficient of variation were less than $20 \%$. Measurement uncertainty was lower than $22 \%$ for all validated organophosphorus pesticides. The limits of quantification were $10 \mu \mathrm{g} / \mathrm{kg}$ for all compounds and allowed determination of residues at, or even below, the maximum residue limits set by the European Union. The satisfactory z-score results of international proficiency tests confirm good accuracy, reproducibility, and reliability of the developed method.
\end{abstract}

Key words: milk, organophosphorus pesticides, gel permeation chromatography.

Organophosphorus pesticides (OPPs) are esters, amides, or thiol derivatives of phosphoric or phosphonic acid. They are still used, mainly as insecticides, in plant protection and in animal husbandry. OPPs are easily hydrolysed and therefore do not persist in the environment for a very long time. However, their toxicity (highly toxic or moderately toxic), with the possibility of accumulation of some of them, especially those, which are fat soluble, in animal tissues, milk, and eggs can cause a risk for human health. The occurrence of pesticide residues in milk is a matter of public health concern, since milk and dairy products are widely consumed by infants, children, and adults. The presence of organophosphorus pesticide (OPP) residues in milk is still reported $(5,9,13)$. The main causes of OPP residues in milk are carried over processes from contaminated feed, grass or corn silage, and veterinary use against parasites and insects by application of pesticides directly on the dairy cattle, in barn or in dairy plants.

To protect the health of consumers and to eliminate unsafe food, as well as to comply with the requirements of international food trade, the maximum residue limits (MRLs) of pesticide in food were laid down in Regulation (EC) 396/2005 (12). For studied pesticides, MRLs in milk have been established at the analytical limit of determination (between 10 and 50 $\mu \mathrm{g} / \mathrm{kg})$.

Several methods have been published for the determination of pesticide residues in milk samples by different separation and detection techniques. Matrix solid-phase dispersion (MSPD) and solid phase extraction (SPE) are frequently used techniques for cleanup of milk extracts in pesticide residue analysis (7, 8,10 ). Solid-phase micro extraction (SPME) was found, in recent years, to be a promising analytical technique for the determination of pesticide residues in milk (2). Gel permeation chromatography (GPC) has been applied to the determination of OPP residues in food of animal origin (meat, milk, eggs) as a purification step of fatty extracts $(4,6)$.

The aim of the study was to develop and validate an analytical method with GPC cleanup for the determination of 13 OPP residues in cow's milk samples, which fulfils the requirements of European regulations regarding the official controls of chemical residues in food of animal origin.

\section{Material and Methods}

Reagents. Acetone, cyclohexane, ethyl acetate, petroleum ether, toluene, 2,2,4-trimethylpentane 
(isooctane), n-hexane (Baker Ultra Resi-Analyzed) were obtained from J.T. Baker (The Netherlands). Bio Beads S-X3 (200-400 mesh) were purchased from Bio-Rad (USA). Silica gel $60(0.063-0.200 \mathrm{~mm})$, supplied by Merck (Germany), was heated at $130^{\circ} \mathrm{C}$ for at least $5 \mathrm{~h}$, and then deactivated with $1.5 \%$ of water before use. Anhydrous sodium sulphate (POCH, Poland) was heated at $500^{\circ} \mathrm{C}$ for at least $5 \mathrm{~h}$. Water was purified through a Mili-Q Plus system from Millipore (USA).

Analytical standards of OPPs were purchased from Dr Ehrenstorfer (Germany) and IPO (Poland). Stock $(1,000 \mu \mathrm{g} / \mathrm{mL})$ and intermediate $(10 \mu \mathrm{g} / \mathrm{mL})$ standard solutions were made in cyclohexane and stored in the dark at a temperature below $-18^{\circ} \mathrm{C}$. The mixed standard solutions of all pesticides were prepared by appropriate dilutions of standard solution $(10 \mu \mathrm{g} / \mathrm{mL})$ with cyclohexane or acetone. These solutions with appropriate OPP levels were used for calibration curve, studying linearity, and spiking blank milk samples, and were stored in brown bottles in the dark at $4^{\circ} \mathrm{C}$.

Equipment and working conditions. OI Analytical (USA) automated system GPC AutoPrep 2000 with UV detector $(\lambda=254 \mathrm{~nm})$, equipped with two columns of different bed amount were used: (A) a glass column, $600 \mathrm{~mm} \times 30 \mathrm{~mm}$ packed with $60 \mathrm{~g}$ of Bio Beads S-X3 (according to EN 1528) and (B) an Optima PTFE, $300 \mathrm{~mm} \times 21 \mathrm{~mm}$ packed with $21 \mathrm{~g}$ of Bio Beads S-X3. Agilent Technologies gas chromatograph, model 7890 A, equipped with 7683 B series autosampler, split/splitless injector, and flame photometric detector (FPD) for determination of OPP was used. Chromatographic separation was achieved on a DB 1701 capillary column $(30 \mathrm{~mm} \times 0.25 \mathrm{~mm}$ ID $\times 0.25 \mu \mathrm{m}$ film thickness, J\&W Scientific, USA). The following oven temperature program was used: initial temperature of $85^{\circ} \mathrm{C}$ hold for $0.7 \mathrm{~min}$, increase to $180^{\circ} \mathrm{C}$ at $40^{\circ} \mathrm{C} / \mathrm{min}$ and hold for $5 \mathrm{~min}$, increase to $220^{\circ} \mathrm{C}$ at $35^{\circ} \mathrm{C} / \mathrm{min}$ and hold $5 \mathrm{~min}$, increase to $235^{\circ} \mathrm{C}$ at $90^{\circ} \mathrm{C} / \mathrm{min}$ and hold for $3.9 \mathrm{~min}$, and then increase to $270^{\circ} \mathrm{C}$ at $120^{\circ} \mathrm{C} / \mathrm{min}$ and hold for $18.4 \mathrm{~min}$. The total run time of chromatographic analysis was $37 \mathrm{~min}$. The injector and detector were operated at $280^{\circ} \mathrm{C}$ and $250^{\circ} \mathrm{C}$, respectively. The carrier gas was helium with flow rate of $1 \mathrm{~mL} / \mathrm{min}$. The injection volume was $2 \mu \mathrm{L}$ in the pulsed splitless mode. The GC was controlled by ChemStation software.

Extraction. An accurately weighed $20 \mathrm{~g}$ of milk was placed in centrifuge tube, mixed with $40 \mathrm{~mL}$ of acetone and $60 \mathrm{~mL}$ of petroleum ether, and homogenised for $3 \mathrm{~min}$ at $10,000 \mathrm{rpm}$. The sample was then centrifuged at $3,000 \mathrm{rpm}$, at $2^{\circ} \mathrm{C}$ for $15 \mathrm{~min}$. After centrifugation, the solvent layer was transferred to the separatory funnel. The lower layer was dumped. The upper solvent layer was passed through anhydrous sodium sulphate to the round-bottom flask and concentrated to small volume by rotary evaporator (water bath at $35^{\circ} \mathrm{C}$; reduced pressure), and evaporated to near dryness under a gentle stream of nitrogen.

GPC cleanup. The concentrated extract was carefully transferred with mixture of cyclohexane and ethyl acetate in the ratio $1: 1$, filled to $5 \mathrm{~mL}$ volume and mixed well. The extract was injected into the GPC system for cleanup using the following conditions: mobile phase, mixture of cyclohexane and ethyl acetate in the ratio $1: 1$; flow rate, $5 \mathrm{~mL} / \mathrm{min}$; injection volume, $2.5 \mathrm{~mL}$; dump time, $8 \mathrm{~min}$; collect time, $6 \mathrm{~min}$; wash time, $5 \mathrm{~min}$. The first fraction of the eluant $(40 \mathrm{~mL})$ containing lipids was discarded. The second fraction (30 $\mathrm{mL}$ ) containing OPPs were collected and, after addition of $5 \mathrm{~mL}$ of isooctane, concentrated to small volume by rotary evaporator. The total GPC cleanup time was 19 min per sample.

SPE cleanup. The concentrated extract from GPC in isooctane was carefully transferred onto the column containing $1 \mathrm{~g}$ of silica gel (deactivated with $1.5 \%$ water) with a layer of anhydrous sodium sulphate, rinsed beforehand with $10 \mathrm{ml}$ of $\mathrm{n}$-hexane. The pesticides were eluted with $10 \mathrm{~mL}$ mixture of toluene and acetone in the ratio $4: 1$. The eluate was first evaporated to near dryness on a rotary evaporator (water bath at $40^{\circ} \mathrm{C}$; reduced pressure), and then to dryness under a gentle stream of nitrogen. For GC analysis extracts were dissolved in $1 \mathrm{~mL}$ of cyclohexane.

Method of validation. The raw cow's milk samples free from OPPs were used as blank to spike aliquots for validation studies and to prepare matrix matched standards for calibration. For evaluation of recovery and precision (repeatability and withinlaboratory reproducibility), the samples were spiked according to the expected concentration levels, mixed thoroughly, and left for $1 \mathrm{~h}$. The spiked samples at each concentration level were analysed in three series, each by different analyst, each on the different day, and each in six replicates. The accuracy determined by average recovery were calculated by comparing the determined concentrations of spiked samples to their target levels. The precision was determined by calculating the coefficient of variation (CV) value. The linearity was checked using mixed standard solution and analysing each of them in duplicate at five concentrations between 100 and $1,000 \mu \mathrm{g} / \mathrm{mL}$. The limit of quantification (LOQ) of OPPs was evaluated as the minimum concentration of the analyte that can be quantified with acceptable accuracy and precision. The uncertainty was estimated in accordance with the recommendations of Eurachem/CITAC Guide (Second edition, 2000).

\section{Results}

Using a capillary column with a low/mid polarity (14\%-cyanopropyl-phenyl)-methylpolysiloxane stationary phase with optimised temperature conditions allowed to separate of all pesticides determined by this method. No interference peaks were observed in the retention times of the analytes. Typical chromatograms of standard solution of OPPs, extract of blank milk and spiked milk extract are shown in Fig. 1.

At the evaluation step of cleanup method, two different GPC columns were optimised and appropriate dump and collect times were determined. All run parameters except injection volume were the same. On column A $5 \mathrm{~mL}$ while on column B $2.5 \mathrm{~mL}$ of the extract were injected, respectively. For comparison of 
elution profiles blank milk extracts spiked with OPPs before GPC were fractionated on both columns. The OPPs elutes from the column A in the volume range of $121-165 \mathrm{~mL}$. The similar eluting profile was stated for the column B, but the time, in which OPPs eluted was about three times shorter, OPPs were detected in the fraction from 41 to $65 \mathrm{~mL}$. All the GPC elution ranges for all studied OPPs are listed in Table 1. From the column A pesticides were eluted from 24 to $33 \mathrm{~min}(45$ $\mathrm{mL}$ ) while from the column B they were eluted from 8 to $13 \mathrm{~min}(35 \mathrm{~mL})$. For the validation study column $\mathrm{B}$, filled with $21 \mathrm{~g}$ of Bio Beads S-X3 was chosen.

In order to confirm that the developed method is suitable for its intended use and fulfills the aim of the study, the validation process with the recommendations of the document SANCO/12495/2011 (Method of validation and quality control procedures for pesticide residues analysis in food and feed) was carried out. Estimated validation parameters of the method were satisfactory. The accuracy of the method was expressed as mean recovery, and it was higher than $70 \%$ for all OPPs at all spiked levels. The method showed good repeatability and within-laboratory reproducibility with
$\mathrm{CV}$ values lower than $5.6 \%$ and $15.4 \%$, respectively. Regression coefficients $\left(\mathrm{R}^{2}\right)$ values of at least 0.999 showed good linearity. All validation results are listed in Table 2 .

\section{Discussion}

Due to the complex nature of animal origin samples and the presence of fat, selection of the appropriate technique of preconcentration and purification of the analytes, and its optimisation is the most laborious, but very important aspect of the analysis. A lot of different cleanup methods were used in the determination of pesticides in milk but there is no universal technique, which would be entirely better than the others in terms of all analytical scopes.

Among proposed cleanup methods MSPD and DSPE were stated as the most promising to the pesticides analysis in milk, but some drawbacks of these methods were stated. Lehotay et al. (7) established that there is a dependence between recovery of pesticides versus fat content of the sample in MSPD and DSPE.
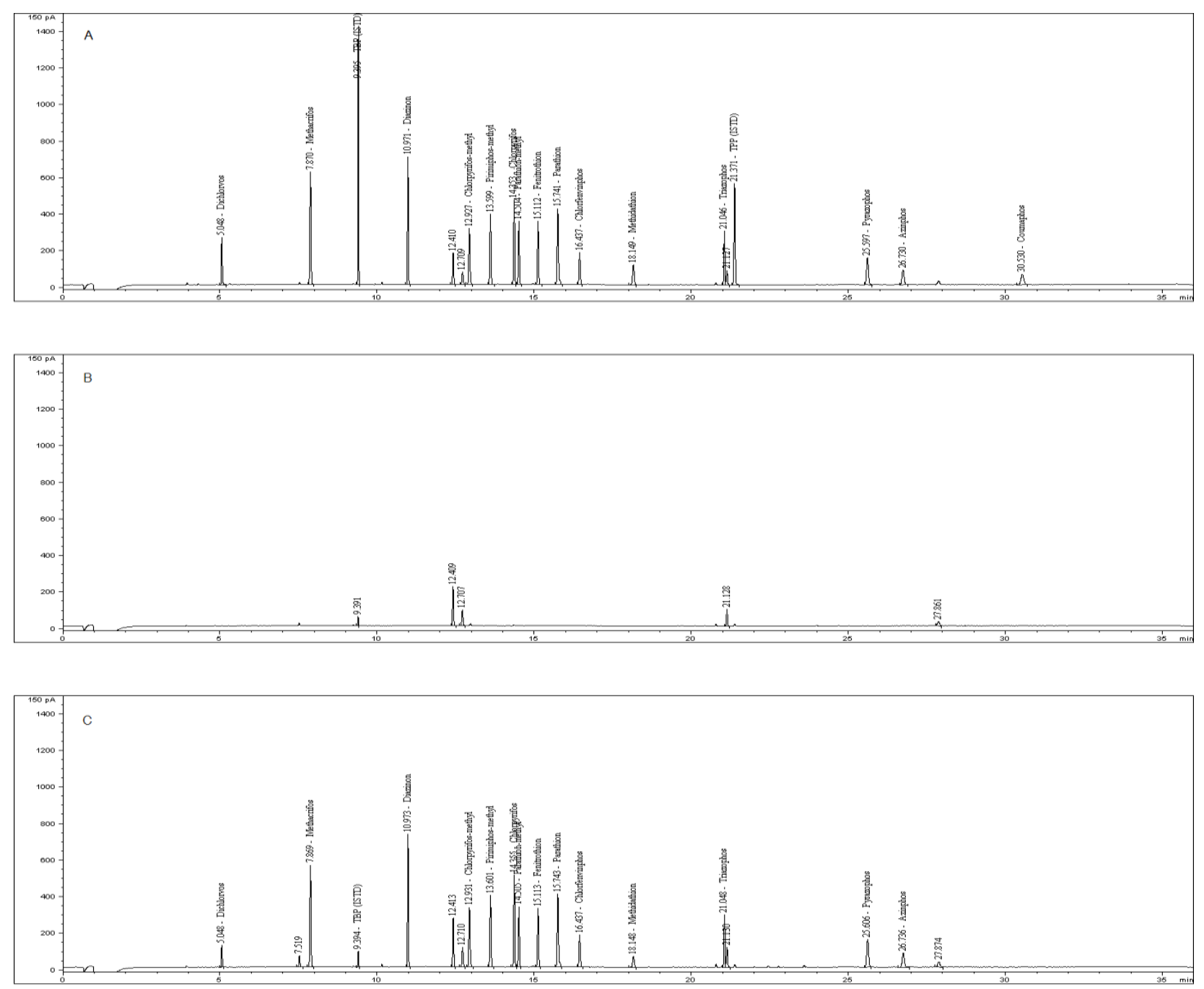

Fig. 1. GC-FPD chromatograms: A-matrix matched standard solution of OPPs at $100 \mu \mathrm{g} / \mathrm{L}$, B-blank milk extract, C-milk spiked with OPPs at the level of $10 \mu \mathrm{g} / \mathrm{kg}$ 
Table 1

Eluting profiles of OPPs on GPC columns

\begin{tabular}{lcc}
\hline \multirow{2}{*}{ Pesticide } & \multicolumn{2}{c}{ GPC elution volume range (mL) } \\
\cline { 2 - 3 } & Column A, Bio Beads S-X3, 60 g & Column B, Bio Beads S-X3, 21 g \\
\hline Azinphos & $143-158$ & $46-65$ \\
Chlorfenvinphos & $121-128$ & $41-55$ \\
Chlorpyrifos & $128-142$ & $41-60$ \\
Chlorpyrifos-methyl & $136-158$ & $41-65$ \\
Diazinon & $121-135$ & $41-55$ \\
Fenitrothion & $136-158$ & $46-60$ \\
Methacrifos & $128-150$ & $46-55$ \\
Methidathion & $158-165$ & $51-65$ \\
Parathion & $121-142$ & $41-60$ \\
Parathion-methyl & $136-158$ & $46-60$ \\
Pirimiphos-methyl & $128-150$ & $41-55$ \\
Pyrazophos & $128-142$ & $41-60$ \\
Triazophos & $121-158$ & $41-60$ \\
\hline
\end{tabular}

Table 2

Validation results (linearity, recovery, precision, and uncertainty) of OPP determination by GC-FPD in milk

\begin{tabular}{|c|c|c|c|c|c|c|}
\hline Pesticide & Linearity & $\begin{array}{c}\text { Spiked level } \\
\mu \mathrm{g} / \mathrm{kg}\end{array}$ & $\begin{array}{l}\text { Recovery } \\
\%(n=18)\end{array}$ & $\begin{array}{l}\text { Repeatability } \\
\text { CV, \% }(n=6)\end{array}$ & $\begin{array}{c}\text { Within-lab } \\
\text { reproducibility } \\
\mathrm{CV}, \%(\mathrm{n}=18)\end{array}$ & $\begin{array}{c}\text { Measurement } \\
\text { uncertainty } \\
\% \\
\end{array}$ \\
\hline \multirow{3}{*}{ Azinphos } & \multirow{3}{*}{$\begin{array}{c}\mathrm{y}=0.98 \mathrm{x}-13.59 \\
\mathrm{R}^{2}=1.000\end{array}$} & 10 & 98.4 & 2.2 & 7.6 & \multirow{3}{*}{20.0} \\
\hline & & 20 & 95.4 & 1.1 & 6.8 & \\
\hline & & 30 & 91.5 & 2.1 & 3.0 & \\
\hline \multirow{3}{*}{ Chlorfenvinphos } & \multirow{3}{*}{$\begin{array}{c}\mathrm{y}=1.65 \mathrm{x}+22.68 \\
\mathrm{R}^{2}=0.999\end{array}$} & 10 & 95.6 & 2.1 & 8.1 & \multirow{3}{*}{20.9} \\
\hline & & 20 & 94.2 & 1.4 & 4.7 & \\
\hline & & 30 & 87.6 & 1.2 & 2.9 & \\
\hline \multirow{3}{*}{ Chlorpyrifos } & \multirow{3}{*}{$\begin{array}{c}\mathrm{y}=4.57 \mathrm{x}+20.55 \\
\mathrm{R}^{2}=0.999\end{array}$} & 10 & 103.8 & 1.2 & 3.9 & \multirow{3}{*}{10.7} \\
\hline & & 20 & 99.9 & 1.7 & 4.1 & \\
\hline & & 30 & 96.1 & 2.0 & 4.2 & \\
\hline \multirow{3}{*}{$\begin{array}{l}\text { Chlorpyrifos- } \\
\text { methyl }\end{array}$} & \multirow{3}{*}{$\begin{array}{c}\mathrm{y}=3.24 \mathrm{x}-13.68 \\
\mathrm{R}^{2}=1.000\end{array}$} & 10 & 103.8 & 1.9 & 4.6 & \multirow{3}{*}{12.8} \\
\hline & & 20 & 96.4 & 2.0 & 4.8 & \\
\hline & & 30 & 92.8 & 1.9 & 3.9 & \\
\hline \multirow{3}{*}{ Diazinon } & \multirow{3}{*}{$\begin{aligned} \mathrm{y}= & 6.58 \mathrm{x}+54.49 \\
& \mathrm{R}^{2}=1.000\end{aligned}$} & 10 & 100.3 & 2.7 & 7.4 & \multirow{3}{*}{20.6} \\
\hline & & 20 & 98.1 & 1.5 & 4.5 & \\
\hline & & 30 & 84.2 & 1.9 & 5.2 & \\
\hline \multirow{3}{*}{ Fenitrothion } & \multirow{3}{*}{$\begin{array}{c}\mathrm{y}=3.85 \mathrm{x}-56.75 \\
\mathrm{R}^{2}=0.999\end{array}$} & 10 & 102.3 & 2.4 & 4.3 & \multirow{3}{*}{12.0} \\
\hline & & 20 & 94.8 & 1.0 & 4.1 & \\
\hline & & 30 & 91.0 & 1.5 & 3.7 & \\
\hline \multirow{3}{*}{ Methacrifos } & \multirow{3}{*}{$\begin{array}{c}\mathrm{y}=6.06 \mathrm{x}+15.42 \\
\mathrm{R}^{2}=1.000\end{array}$} & 10 & 86.3 & 3.3 & 4.5 & \multirow{3}{*}{11.8} \\
\hline & & 20 & 73.0 & 5.6 & 12.5 & \\
\hline & & 30 & 73.1 & 1.5 & 7.3 & \\
\hline \multirow{3}{*}{ Methidathion } & \multirow{3}{*}{$\begin{array}{c}\mathrm{y}=3.14 \mathrm{x}-22.89 \\
\mathrm{R}^{2}=1.000\end{array}$} & 10 & 94.8 & 1.9 & 4.8 & \multirow{3}{*}{14.9} \\
\hline & & 20 & 91.4 & 1.4 & 5.4 & \\
\hline & & 30 & 88.0 & 1.6 & 2.8 & \\
\hline \multirow{3}{*}{ Parathion } & \multirow{3}{*}{$\begin{array}{c}\mathrm{y}=4.25 \mathrm{x}+22.16 \\
\mathrm{R}^{2}=0.999\end{array}$} & 25 & 101.7 & 2.2 & 5.2 & \\
\hline & & 50 & 98.7 & 1.4 & 3.2 & 8.7 \\
\hline & & 75 & 92.8 & 2.3 & 3.5 & \\
\hline & & 10 & 99.9 & 2.2 & 4.8 & \\
\hline Parathion-methyl & $\begin{array}{c}y=4.02 x-73.16 \\
R^{2}=0999\end{array}$ & 20 & 92.8 & 1.7 & 3.9 & 10.7 \\
\hline & & 30 & 87.6 & 2.3 & 3.9 & \\
\hline & & 25 & 102.5 & 2.7 & 5.7 & \\
\hline Pirimiphos-methyl & $\begin{array}{c}y=3.56 x+43.77 \\
R^{2}=0090\end{array}$ & 50 & 98.8 & 1.6 & 4.0 & 10.8 \\
\hline & & 75 & 92.4 & 2.3 & 4.1 & \\
\hline & & 10 & 103.7 & 2.2 & 7.4 & \\
\hline Pyrazophos & $\begin{array}{c}y=1.39 x+21.66 \\
R^{2}=0999\end{array}$ & 20 & 98.2 & 2.1 & 7.6 & 21.3 \\
\hline & & 30 & 97.3 & 1.7 & 2.1 & \\
\hline & $y=314 x-2290$ & 10 & 96.7 & 5.0 & 8.1 & \\
\hline Triazophos & $y=3.14 x-22.90$ & 20 & 106.2 & 1.4 & 15.4 & 21.2 \\
\hline & $\mathrm{R}^{2}=1.000$ & 30 & 92.2 & 1.5 & 2.8 & \\
\hline
\end{tabular}

Bolded values - MRL, analytical limit of determination acc. to Reg. (EC) 396/2005 
Dagnac et al. (1) also used DSPE as part of fast multi-residue method of pesticide analysis in raw bovine milk, but chlorpyrifos showed recovery lower than $40 \%$. Chlorpyrifos residues were stated as main OPP residues in raw milk, therefore the method of their determination should be characterised by a proper recovery (5). On the contrary to MSPD, DSPE, or SPE cleanup techniques, the GPC is more universal with regard to the fat content in the sample. The method described in the paper was applied with satisfactory results for determination of OPP residues in dairy products other than milk, such as butter fat and cream, which were the test materials in the proficiency test (EUPT) organised by the European Union Reference Laboratory for Pesticides in Food of Animal Origin, CVUA, Freiburg, Germany.

GPC cleanup is an excellent technique for quantitative separation of OPP from the fatty matrices. It performs selective removal of high and medium molecular size impurities such as lipids, pigments, and proteins from food extract. Frenich et al. (3) took the main advantage of this cleanup technique, because polar and non-polar substances can be isolated and recovered for analysis, and two Envirogel GPC columns (150 $\mathrm{mm} \times 19 \mathrm{~mm}$ and $300 \mathrm{~mm} \times 19 \mathrm{~mm}$, respectively) packed with styrenedivinylbenzene copolymer for cleanup 45 pesticides from animal muscles can be used. Pang et al. (11) used GPC column $(400 \mathrm{~mm} \times 25 \mathrm{~mm})$ packed with Bio Beads S-X3 in validation study on 660 pesticide residues in animal tissues. $\mathrm{Wu}$ et al. (14) used GPC column $(300 \mathrm{~mm} \times 25 \mathrm{~mm})$ packed with Bio Beads S-X3 for cleanup of 109 pesticides (including isomers) from different animal meat samples. In all of these methods, the same mixture of cyclohexane and ethyl acetate in the ratio $1: 1$ with a flow rate $5 \mathrm{~mL} / \mathrm{min}$ was used as a mobile phase, but different fractions were collected: from 15 to $22 \mathrm{~min}(35 \mathrm{~mL})$, from 22 to $40 \mathrm{~min}(90 \mathrm{~mL})$, and from 8 to $20 \mathrm{~min}(60 \mathrm{~mL})$.

The proposed method proved to be reliable, accurate, and precise. The results of validation and verification of the method in the international proficiency tests showed its usefulness. Validation parameters obtained for determination of OPP in milk demonstrate that the developed analytical method meets the method performance acceptability criteria (mean recoveries in the range $70 \%-120 \%$, precision with $\mathrm{CV} \leq 20 \%, \mathrm{LOQ} \leq \mathrm{MRL}$ ). Applied GPC column, when compared with conventional column, allowed reducing the amount of organic solvents needed for cleanup, using big capacity of loaded sample (up to $0.5 \mathrm{~g}$ of fat) and shortening about three times the cleanup time per sample. The efficiency of the automated GPC cleanup combined with selective detection by GC-FPD made this method very sensitive and suitable for the use in the analysis of OPP in milk.

\section{References}

1. Dagnac T., Garcia-Chao M., Pulleiro P., Garcia-Jares C., Llompart M.: Dispersive solid-phase extraction followed by liquid chromatography-tandem mass spectrometry for the multi-residue analysis of pesticides in raw bovine milk. J Chromatogr A 2009, 1216, 3702-3709.

2. $\quad$ Fernandez-Alvarez M., Llompart M., Lamas J.P., Lores M., Garcia-Jares C., Cela R., Dagnac T.: Development of solid-phase microextraction gas chromatography with microelectron-capture detection method for a multiresidue analysis of pesticides in bovine milk. Anal Chim Acta 2008, 617, 37-50.

3. Garrido Frenich A., Martínez Vidal J.L., Cruz Sicilia A.D., González Rodríguez M.J., Plaza Bolaños P.: Multiresidue analysis of organochlorine and organophosphorus pesticides in muscle of chicken, pork and lamb by gas chromatography-triple quadrupole mass spectrometry. Anal Chim Acta 2006, 558, 42-52.

4. Hayward D.G., Pisano T.S., Wong J.W., Scudder R.J.: Multiresidue method for pesticides and persistent organic pollutants (POPs) in milk and cream using comprehensive two-dimensional capillary gas chromatography-time-of-flight mass spectrometry. J Agric Food Chem 2010, 58, 5248-5256.

5. Gazzotti T., Sticca P., Zironi E., Lugoboni B., Serraino A., Pagliuca G.: Determination of 15 organophosphorus pesticides in Italian raw milk. Bull Environ Contam Toxicol 2009, 82, 251-254.

6. LeDoux M.: Analytical methods applied to the determination of pesticide residues in foods of animal origin. A review of the past two decades. J Chromatogr A 2011, 1218, 1021-1036.

7. Lehotay S.J., Maštovská K.: Evaluation of two fast and easy methods for pesticide residue analysis in fatty food matrices. J AOAC Int 2005, 88, 630-638.

8. Macedo A.N., Nogueira A.R., Govoni Brondi S.H.: Matrix solid-phase dispersion extraction for analysis of cypermethrin residue in cow's milk. Chromatographia 2009, 69, 571-573.

9. Melgar M.J., Sentaeufemia M., Garcia M.A.: Organophosphorus pesticide residues in raw milk and infant formulas from Spanish nortwest. J Environ Sci Health B 2010, 45, 595-600.

10. Pagliuca G., Gazzotti T., Zironi E., Sticca P.: Residue analysis of organophosphorus pesticides in animal matrices by dual column capillary gas chromatography with nitrogen-phosphorus detection. J Chromatogr A 2005, 1071, 67-70.

11. Pang G.F., Cao Y.Z., Zhang J.J., Fan C.L., Liu Y.M., Li X.M., Jia G.Q., Li Z.Y., Shi Y.Q., Wu Y.P., Guo T.T.: Validation study on 660 pesticide residues in animal tissues by gel permeation chromatography cleanup/gas chromatography-mass spectrometry and liquid chromatography-tandem mass spectrometry. J Chromatogr A 2006, 1125, 1-30.

12. Regulation (EC) No. 396/2005 of the European Parliament and of the Council of 23 February 2005 on maximum residue levels of pesticides in or on food and feed of plant and animal origin and amending Council Directive 91/414/EEC. OJ L 2005, 70.

13. Salas J.H., González M.M., Noa M., Pérez N.A., Díaz G., Gutiérerez R., Zazueta H., Osuna I.: Organophosphorus pesticide residues in Mexican commercial pasteurized milk. J Agric Food Chem 2003, 51, 4468-4471.

14. Wu G., Bao X., Zhao S., Wu J., Han A., Ye Q.: Analysis of multi-pesticide residues in the food of animal origin by GC-MS coupled with accelerated solvent extraction and gel permeation chromatography cleanup. Food Chem 2011, 126, 646-654. 